\title{
DA PEDAGOGIA DO CAPITAL E DE SUA ANTÍTESE: VIOLÊNCIA, (DE)FORMAÇÃO DO TRABALHO E A LUTA PELA FORMAÇÃO HUMANA
}

\author{
Eduardo Chagas ${ }^{1}$ e Fábio José de Queiroz ${ }^{2}$
}

Resumo: O artigo trata sobre as relações entre o capital e os processos de formação humana, buscando mostrar as estratégias da classe capitalista para manter o controle sobre a classe trabalhadora, restringindo as formas de seu acesso ao saber cultural da humanidade e acentuando a separação entre trabalho intelectual e trabalho manual. Tendo como referência, sobretudo, o legado teórico de Marx em O Capital (2013), partimos de duas hipóteses: o capital, ao se valorizar, atua com a força de seus intentos e a violência de seus métodos; junto disso, oferece uma educação fragmentada, elementar e de cunho meramente técnico aos que trabalham sob seu regime. Constatamos, assim, que, em última instância, tal educação se mostra não só mitigada, mas, ao mesmo tempo, refém de um sistema no qual o cerceamento à liberdade do trabalhador, explícito ou não, desempenha papel decisivo. Reafirmamos, não obstante os limites que cercam os processos de educação formal, que os trabalhadores não podem abdicar de uma reivindicação-chave: a luta pelo acesso às objetivações históricas produzidas pela humanidade ao longo do tempo.

Palavras-chave: capital, violência, deformação e formação humana.

\begin{abstract}
The article deals with the relations between capital and the processes of human formation, trying to show the strategies of the capitalist class to maintain control over the working class by restricting the forms of their access to humanity culture and accentuating the separation between intellectual work and manual work. With reference, above all, to Marx's theoretical legacy in Capital (2013), we start from two hypotheses: the capital, when valuing itself, acts with the force of its attempts and the violence of its methods; next to this, offers a fragmented, elementary and purely technical education to those who work under its regime. We verified that in the last instance this education not only shows itself mitigated but also hostage of a system in which the restriction to the freedom of the worker, explicit or not, plays a decisive role. We reaffirm, despite the limits that surround the processes of formal education, that workers can not relinquish a key claim: the struggle for access to historical objectifications produced by mankind over time.
\end{abstract}

Keywords: Capital, violence, deformation e formation.

\section{Introdução:}

Neste artigo, estudamos os elos que articulam a ação do capital e os processos de formação humana tendo como alvo prioritário a classe trabalhadora. Partimos de duas hipóteses: o capital, ao se valorizar, atua com violência como se trouxesse consigo, notadamente, não só a voracidade econômica, mas a força de seus intentos e a brutalidade de seus métodos; junto disso, como segundo requisito, oferece uma educação aos que trabalham debaixo de seu regime, que, em última instância, se mostra

\footnotetext{
${ }^{1}$ Doutor em Filosofia pela Universität von Kassel (KASSEL, ALEMANHA), é professor efetivo (associado) do Curso de Filosofia e do Programa de Pós-Graduação em Filosofia da Universidade Federal do Ceará (UFC) e professor colaborador do Programa de Pós-Graduação em Educação Brasileira da FACED - UFC. Coordenador do Grupo de Estudos Marxistas - GEM -, vinculado ao Eixo Marxismo, Teoria Crítica e Filosofia da Educação, e ao Programa de Pós-Graduação em Educação Brasileira da FACED - UFC. Bolsista Pesquisador do CNPq e Orientador do Programa Jovens Talentos/CNPQ.

${ }^{2}$ Doutor em Sociologia pela Universidade Federal do Ceará (UFC), é professor efetivo (adjunto) do Departamento de História da Universidade Regional do Cariri (URCA) e professor convidado do Mestrado em Educação Brasileira da FACED - UFC. Coordenador do Grupo de Pesquisa Marx, Luta de Classes, Estado, Ideologia e Revolução/URCA.
} 
não só mitigada, mas, ao mesmo tempo, refém de um sistema em que o cerceamento à liberdade do trabalhador, explícito ou não, desempenha papel de franco protagonismo.

Ao tentar desenvolver essas hipóteses avançamos para um terceiro pressuposto: malgrado os limites que cercam os processos de educação formal, no âmbito do domínio do capital, os trabalhadores não podem abdicar de uma reivindicação-chave: a luta pelo acesso às objetivações históricas produzidas pela humanidade ao longo do tempo. Essa inferência implica pleitear o direito à educação pública como condição necessária da formação humana daqueles que vivem da venda de sua força de trabalho. As contradições que marcam a categoria trabalho também se espraiam quando tratamos do complexo da educação. Em larga medida, ambos exalam dimensões positivas e negativas. É para essa complexidade que se deve voltar todo aquele que almeja a emancipação da classe trabalhadora.

Nessa perspectiva, nos apoiamos inicialmente no livro I de O capital, de Karl Marx, tomando-o não como uma receita para os problemas do século XXI, mas, necessariamente, como excelente ponto de partida para estudos e reflexões nos quais os laços entre trabalho e educação, em seus múltiplos aspectos, possam ser plenamente desenvolvidos.

\section{Ferocidade do capital, trabalho e deformações na instrução do indivíduo humano}

Quando Marx publicou o livro I de O capital, efetivamente, o capitalismo havia se erguido como sistema "puro" quase que unicamente na Inglaterra. Não por nada, foi esse país que, em última análise, serviu de ilustração para o estudo do modo de produção especificamente capitalista. As conquistas e horrores do capital, que se espalhariam pelo mundo, nos decênios seguintes, de fato, se revelaram ali em primeiro lugar. Com a passagem do tempo, e a expansão capitalista, mudam as personagens e os lugares, mas não a natureza do sacrifício desferido.

Prefigurando esse processo, a sociedade inglesa do século XIX oferece a MarX sinais precursores desse movimento pouco altruísta do capital. Quando das exigências de que o Estado promovesse a instrução pública para os filhos da classe trabalhadora, não só afloraram instituições escolares que receberam os rebentos dessa classe, mas nesses estabelecimentos de ensino se testemunharam como as classes dirigentes entendiam (e ainda entendem) a natureza desses espaços de formação voltados ao atendimento das demandas das famílias proletárias. Aliás, essas demandas começaram,

n. 9

Setembro - Dezembro 2016

p. $100-112$ 
também, a se tornar exigências de certos ramos da produção industrial, carentes de uma mão-de-obra que recebesse uma formação escolar mínima.

Desse modo, em torno da produção, diretamente,

Surge a simples separação dos trabalhadores em qualificados e não qualificados. Para estes últimos, os custos de aprendizagem desaparecem por completo e, para os primeiros esses custos são menores, em comparação com o artesão, devido à função simplificada. $\mathrm{E}$, ambos os casos diminui o valor da força de trabalho. (MARX, 2013, p. 424).

Como se observa, o capital consegue reduzir seus custos com a preparação da força de trabalho sob o signo da maquinaria. As máquinas simplificam as tarefas e a simplificação das tarefas define o lugar e a profundidade do processo formativo do trabalhador. Mesmo o mais qualificado deles não traz embutidas na sua formação despesas exageradas intrínsecas às exigências de qualificação. Ainda hoje, certas tarefas da indústria exigem trabalhadores qualificados de modo mínimo. Inversamente, outra parte da atividade produtiva pode ser realizada pelo trabalhador cujo aprendizado, não raro, ocorre no âmbito da própria experiência fabril. O tarimbeiro não é o proletário do século XIX. Ainda hoje, ele é reclamado pelo sistema industrial. Certos ramos da produção capitalista, frequentemente, requerem esse trabalhador simples como uma linha inserida na agulha e a constatação desse fato se torna um capítulo muito particular dessa história, de suas notações fugidias e de sua compreensão mais global.

O aparecimento de funções novas, complementares ou distintas das até então existentes, durante certo tempo, exige novos investimentos com o intuito de equilibrar a procura de profissionais qualificados com a demanda industrial. Por exemplo: quando a maquinaria começou a ocupar espaço privilegiado, ao longo do século XIX, ocorreram situações que, à primeira vista, impeliram os capitalistas a se aterem a tarefa de cobrar do Estado soluções para o impasse transitório que se abriu. Essa questão não deixou de ser notada por Marx: "Exceções ocorrem na medida em que a decomposição do processo de trabalho gera funções novas e abrangentes que no artesanato não existiam, ou pelo menos não na mesma extensão" (2013, p. 424).

Nesses casos, momentaneamente, não se deve admitir que, de modo categórico, ocorram aí situações nas quais prevaleça a redução do valor da força de trabalho. Tratase, no entanto, de circunstâncias contingentes e, provavelmente, são resolvidas no curso de poucos anos. Ademais, a história demonstra que os custos de aprendizagem nem 
sempre são pagos pelos capitalistas. Grande parte das vezes, o capital mobiliza o Estado que ou subsidia de modo parcial a aprendizagem ou simplesmente a patrocina diretamente. Nos dois casos, o financiamento do exercício inicial de instrução da mãode-obra se realiza mediante a utilização do fundo público.

A questão é: até que ponto se pode falar desses processos como exemplos de formação humana? Até que ponto não se deve reconhecer como insuspeita a hipótese de uma polaridade constitutiva entre formação e deformação humana?

Quando na Inglaterra da primeira metade do século XIX, cresceram requisições de premente instrução pública para as famílias proletárias, não faltaram oportunidades para se demonstrar como o capital e o Estado trataram o problema com desrespeito e despudor, tanto no tocante à qualidade do ensino quanto aos locais onde eram realizadas atividades consideradas como institucionalmente formativas. Assim,

Antes que se promulgasse a lei fabril de 1844 , não era raro que os certificados de frequência escolar viessem assinados com uma cruz pelo professor ou professora, pois eles mesmos não sabiam escrever. (MARX, 2013, p. 473).

$\mathrm{Na}$ esteira dessas deformidades elementares, "os inspetores de fábrica denunciaram a situação vergonhosa dos locais chamados de escolas e cujos certificados eles tinham de aceitar como plenamente válidos do ponto de vista legal" (idem). Esses fatos testemunham como os capitalistas estampavam vivamente o seu real descontentamento com relação às cláusulas educacionais que vinham ao mundo, não sob o beneplácito dos industriais, mas apesar de seu desconforto e repulsa. Confirma igualmente como a qualidade da formação humana não constitui um genuíno propósito dos capitalistas e daqueles que representam seus interesses no âmbito das instituições estatais.

Agora, à medida que a aprendizagem se torna indispensável para o cumprimento de certas funções produtivas, o capital não deixa de se empenhar com vistas a conceder ao Estado o encargo de instruir o trabalhador ou a futura mão-de-obra no que se faz necessário quanto ao adestramento da sua capacidade producente. As mudanças que aconteceram na instrução pública, não só na Inglaterra, mas no mundo inteiro, desde meados do século XIX, no entanto, não nos autoriza a crer que a instrução pública para família trabalhadora se tornou qualitativamente distinta e naturalmente humana. É uma situação próxima do que aconteceu com a aplicação da maquinaria, em larga escala, no

\begin{tabular}{|l|l|l|l|l|}
\hline Qovista Qialectus & Ano 3 & n. 9 & Setembro - Dezembro 2016 & p. $100-112$ \\
\hline
\end{tabular}


processo de produção. Do século XIX para cá, essa aplicação mudou significativamente, mas, do ponto de vista da classe trabalhadora, a maquinaria e a grande indústria, em vez de aumentar o tempo livre da classe que vive do trabalho, a tornou ainda mais refém de sua potência hostil. A intensificação da jornada de trabalho, ao lado de horas extras custosas e alienantes, apenas demonstra que o capital maneja o progresso técnico, não a favor, mas contra aqueles que vivem da venda de sua força de trabalho. No caso da educação para o trabalhador, as mudanças que se deram ao longo de mais de um século e meio, a datar da publicação de $O$ capital, não conseguiram dotar o dono da força de trabalho de uma práxis que acrescentasse um novo significado a sua existência, humanizando a sua natureza, naturalizando a sua humanidade. Esses fatos somente demonstram como o capital maneja a instrução pública, não a favor, mas contra aqueles que vivem da venda de sua capacidade de trabalho.

No que diz respeito a essa questão, a leitura de $O$ capital nos autoriza a emitir um juízo inicial: a educação do trabalhador refulge um brilho quase opaco, pois funciona mais como indício do que como obra completa. Esse padrão de violência não é inteiramente tipificado. Ao trabalhador é oferecido um meio-estudo quando, com efeito, um meio-estudo não é exatamente o estudo de que necessita aquele que produz a riqueza material da sociedade e dela recebe unicamente a pobreza instrutiva. Numa sociedade fundada na desigualdade, a instrução desigual é a norma que se impõe. Essa compreensão tem como base o pressuposto de que a educação não pode ser igual para classes sociais cujos interesses e papéis históricos são radicalmente distintos. A esse respeito, os exemplos que emanam da obra magna de Marx são suficientemente congruentes.

Assim, em situações nas quais o Estado opera com políticas públicas de formação de mão-de-obra, ou de constituição de escolas profissionais, nota-se a mão invisível do capital indicando e propondo direções que o favoreçam; tendo em vista essa perspectiva, as deformidades desse tipo de formação sugerem que estamos perante uma caricatura daquilo que se pretende elevar até ao topo onde deveria se instaurar a riqueza humana. Do alto da montanha, distingue-se unicamente a caricatura capitalista da formação humana, sorridente e plácida, como se não cansasse de repetir o velho estribilho: "trabalhador, não te esquece de tomar nota de teus deveres"!

n. 9

Setembro - Dezembro 2016

p. $100-112$ 


\section{A pedagogia de ferro do capital: capitalismo, formação humana e violência}

A tolerância do capital tem como limite a sua existência como relação social. A começar desse limite, a violência tácita se torna violência aberta. Logo, não há como superar o capital sem conjurar a violência que o acompanha. Isso significa quase recordar uma lição impregnada de história. Entendê-la é alcançar o que Jorge Ortega nos atira no rosto: "aproxima a lanterna do abismo/para buscar a chave entre rochedos" (2016, p. 67).

Nessa perspectiva, cabe enfatizar: a pedagogia do capital é uma pedagogia de ferro. Aos que atuam ativamente no mercado de trabalho, ela orienta a mais feroz exploração. Aos que são atirados além de suas fronteiras, ela sinaliza a mais sanguinária das expropriações, a do próprio direito ao trabalho. A violência muda de forma, mas a sua raiz é a mesma, e diz respeito aos métodos violentos com os quais o capital submete o trabalho. As tentativas de reformas, desprezando a necessidade de ruptura radical com essa ordem, i.e., de rompimento com as suas raízes, apenas aparentam mudar o que, em última análise, permanece intocado.

A redução de salários, o desemprego, a escassez e as esmolas são os meios pelos quais a violência do capital se manifesta em seus múltiplos efeitos. Essas modalidades de coerção, entretanto, não são raios no céu azul; elas são inerentes a esse sistema, que não existe sem ela. As tentativas de pacificar o regime social capitalista tem a mesma eficácia de subir ao céu escalando um pé de feijão. Isso funciona unicamente nos relatos ficcionais. Enquanto reformadores, de todo tipo, formulam remédios milagrosos para restaurar a paz, sem demolir o sistema do capital, a exploração da força de trabalho se torna, mais e mais, inescrupulosa. Esse é outro enunciado da pedagogia de ferro do capital.

Do trabalho de tipo domiciliar a fábrica, da fábrica ao trabalho domiciliar, da empresa-mãe às empresas associadas e das segundas para primeira, por fios invisíveis, o capital se move e submete o corpo do trabalhador às condições rapaces que alimentam, revigoram e valorizam este mesmo capital. Nesse contexto, a pobreza humano-social rouba do trabalhador não só as condições de trabalho mais essenciais, mas o aliena de usufruir das capacidades que o seu corpo opera. Doutro lado, o sonho de enriquecer mediante o trabalho domiciliar, ilude o corpo e a alma, até que ambos derrapem, e o 
corpo desça a terra, enquanto a família reza para que a alma suba ao céu. ${ }^{3}$ Eis outro ensinamento - este bem prático - da pedagogia de ferro do capital.

Não é de espantar que as doenças, os baixos salários e o desemprego que atingem os trabalhadores, apareçam como "condições vitais do capital" e não como expressões de sua brutalidade regular, sem contar que a violência da produção capitalista é incompatível com o que Marx denomina de "produção de seres humanos desenvolvidos em suas múltiplas dimensões" (2013, p. 554). Essa indicação demonstra que a plena formação humana é um anelo que passa ao largo das preocupações do capitalista para com o trabalhador, retido em uma teia de sutilezas e ciladas, que, em última hipótese, mais esconde do que revela o conteúdo da brutalização que se harmoniza com o domínio do capital.

Com efeito, a violência do modo como se organiza o processo de valorização do capital implica na utilização de métodos que induzem à "ignorância" e ao "embrutecimento", ou, expresso de outro modo, determina a degradação física e espiritual da classe que vive da venda de sua força de trabalho. Nesses termos, dir-se-ia que a indústria moderna, eixo em torno do qual se desenvolve o modo de produção especificamente capitalista, impõe um "rito sacrificial ininterrupto" à classe trabalhadora. Eis outro modo de mostrar o significado preciso da noção de pedagogia de ferro. Aqui, a força dos fatos ajuda a evidenciar os pontos mais de fundo dessa pedagogia.

Com o surgimento das máquinas, a conquista da redução da jornada de trabalho e a legislação social e trabalhista, efetivamente, ainda que por um instante, acreditou-se que o capital se civilizara, deixando enterradas no passado as suas explosões bárbaras. Os resultados, de certo modo, são bem distintos das expectativas que se tinha.

Acontece que a grande indústria, ao incorporar os avanços tecnológicos, o faz sempre em detrimento do trabalho e em prol do capital. As utopias de uma sociedade de tempo livre, do ócio, a cada passo, sucumbem ante as asperezas reais do vampiro sedento. Os capitalistas vestem a sua máscara de civilidade, e para provar a coerência entre rosto e máscara, empurram para regiões mais distantes um punhado de indústrias que ignora limites no que diz respeito às questões sociais e ambientais. Esse é outro elemento que pertence ao modelo pedagógico que guia o sistema capitalista. No âmbito desse modelo, o que podem esperar os trabalhadores? Certamente, os embrutecedores

\footnotetext{
${ }^{3}$ Nessa passagem, dialogamos com uma passagem de célebre poema de Alphonsus de Guimarães intitulado "Ismália".
}

n. 9

Setembro - Dezembro 2016

p. $100-112$ 
regimes de trabalho nas minas, a solidão de plataformas sem fim e o submundo de fábricas semiclandestinas, que abusam da mão-de-obra de retirantes e refugiados, e esses são apenas retratos cortados de uma fita interminável de filmes de horror. O que se passa debaixo da terra dura e do galpão aquecido foge aos olhares até dos deuses mais generosos. Desse inferno ninguém há de subir ao céu.

Em todo caso, a essa violência física se combina a crueldade no terreno espiritual, no qual consta a formação humana, que, no caso do conhecimento escolar do trabalhador, é aligeirada e obedece às premências próprias da ordem capitalista, o que explica porque, por exemplo, o ensino e a educação da classe trabalhadora não constituem um sistema prostrado para todo o sempre. Esse sistema se modifica e se diferencia ao longo do tempo, se adaptando às vicissitudes do capital.

Estudando o sistema de instrução pública, à sua época, Marx mostra o caráter cômico do processo de interrogatório dos juízes quanto às pretensões de instrução pública dos trabalhadores das minas e de seus filhos. Demonstra que, tangidos pelo embrutecimento do trabalho, os operários se deparam com dificuldades de melhorar sua educação. Em certas oportunidades, os empresários exigem certificados de adultos e crianças que residem em distritos onde sequer existem escolas noturnas. $\mathrm{O}$ excessivo trabalho nas minas completa a obra na qual a violência social deixa ver como o alvo determinado do capital não é a instrução escrupulosa dos trabalhadores e de seus filhos, até porque, não raro, para o trabalhador, o processo de produção se converte, liminarmente, não em fonte de desenvolvimento humano, mas de degeneração e escravidão. Esse fato influi decisivamente na questão da escolaridade e da formação humana de milhões de homens, mulheres e crianças com origem e inserção no proletariado.

A esse respeito, os representantes da burguesia não se enfastiam de elaborar e aprovar leis que, na aparência, sugerem soluções para o drama que envolve a instrução do proletariado. As legislações eloquentes podem tranquilizar governos e parlamentares, mas, frequentemente, pouco delas conta perante "as espantosas monstruosidades da exploração capitalista” (MARX, 2013, p. 560). Assim, governos e parlamentares ressarcem a sua consciência sem resolver as questões de fundo que dizem respeito à formação humana da massa de operários submetida ao processo de produção. $O$ domínio direto e indisfarçado do capital não anula a legislação fabril, nomeadamente no terreno da educação, mas, decerto, a torna profundamente insuficiente como ferramenta de emancipação do proletariado.

\begin{tabular}{|l|l|l|l|l|}
\hline Qevista Dialectus & Ano 3 & n. 9 & Setembro - Dezembro 2016 & p. $100-112$ \\
\hline
\end{tabular}


No livro Germinal, de Émile Zola, o personagem Deneulin, virtualmente conservador, adverte os seus pares que assim como a nobreza, "pelo seu amor às novidades filosóficas", se torna cúmplice da Revolução Francesa de 1789, a burguesia pode se tornar conivente com a revolução do proletariado. Para ele,

(...) a burguesia faz hoje o mesmo jogo imbecil, com o seu ardor de liberalismo, a sua fúria de destruição, as suas bajulações ao povo... Sim, é a burguesia que afia os dentes ao monstro para ele nos devorar. E há de nos devorar, estejam certos disto! (ZOLA, 1996, p.190).

O que quer dizer Deneulin é que o capital não só martiriza ao proletariado, mas, paradoxalmente, também instrui o seu plantel, e essa instrução é condição necessária para sua formação humana, ainda que nos limites em que os capitalistas buscam sempre ter o controle sobre os trabalhadores. Nesse processo de formação, os que vivem da venda de sua força de trabalho afiam os dentes e, em todo tempo no qual eles defrontam o poder de seu inimigo e instrutor, crescem como ameaça à ordem social existente, ainda que esse processo não seja linear, mas se interrompa e siga o seu curso à base de fluxos e refluxos que se alternam.

Todo esse quadro, no entanto, aguça e amadurece as contradições e antagonismos da forma capitalista e, "ao mesmo tempo, os elementos criadores de uma nova sociedade e os fatores que revolucionam a sociedade velha" (MARX, 2013, p. 571). Nesse cenário, em oposição à pedagogia de ferro do capital, com todo seu séquito de violências, assomam elementos de uma formação humana habilitada a ajudar o trabalhador na sua luta contra as brutalidades de seu antagonista. A luta de classes se converte em momento de grande significado formativo. A ação comum pontifica, educa e disciplina o proletariado. Lentamente, são esmeradas as organizações da classe que reforçam o trabalho de educação básica e de educação política. As pautas das instituições operárias alcançam reivindicações de defesa das escolas públicas e de mais verbas para educação da prole. Mobilizações despertam contingentes inteiros para essa luta. A velha sociedade, então, ainda que por alguns instantes, hesita perante os fatores que ameaçam subvertê-la. Uma nova pedagogia pede passagem. A sua letra é nítida, o seu conteúdo, cristalino, o seu devenir, explicito: os expropriadores serão expropriados.

\begin{tabular}{|l|l|l|l|l|}
\hline Qevista Dialectus & Ano 3 & n. 9 & Setembro - Dezembro 2016 & p. $100-112$ \\
\hline
\end{tabular}




\section{Luta de classes, trabalho e educação}

O usufruto negativo do trabalho no sistema sócio-metabólico do capital não pode nos induzir a esquecer de que "o trabalho desempenhou na história do homem um papel eminentemente educativo", conforme nos recordam Albuquerque e Menezes (2009, p. 94). Como desdobramento desse raciocínio, embora admitam que, na sociabilidade capitalista, o trabalho é fonte de exploração, ressaltam que, mesmo nesse sistema, lado a lado com a negação da dimensão humana, observa-se a presença da afirmação de uma medida humana, que, de modo perceptível, está contida, identicamente, no trabalho. Ademais, questionando o ponto de vista que ignora a dupla determinidade do trabalho na ordem do capital, os autores (há poucos citados) avançam em sua análise, e alcançando o campo da educação, serenamente indagam:

\footnotetext{
Mesmo no interior da sociabilidade capitalista, tendo o trabalho uma dupla determinidade - autoprodução humana e deformação (estranhamento) - não poderia ser entendido ele também como uma dupla determinidade do ponto de vista educativo: fonte de educação (autocompreensão de si e da natureza) ao mesmo tempo que fonte de alienação e destruição humana? (ALBUQUERQUE E MENEZES, 2009, p. 95).
}

Nessa compreensão subjaz a ideia de especificidade da esfera educativa, embora isso não implique negar que o complexo da educação, como complexo social, efetivamente, seja tributário do trabalho. Nesse sentido, no âmbito da luta de classe, os trabalhadores não devem desprezar - quando da elaboração de suas pautas reivindicatórias - o lugar de suas propostas no campo da educação. Assim, nas palavras de Albuquerque e Menezes (2009), a classe que vive da venda de sua força de trabalho não pode se esquivar da "inquietante pergunta": "que proposta educativa, afinal, devem os trabalhadores reivindicar para si como parte de sua luta emancipatória contra o regime do capital?” (p. 98). Para os autores mencionados, os trabalhadores não podem se limitar às reivindicações políticas e econômicas, mas, também, eles devem fazê-lo no campo do ensino escolar, fazendo da educação uma trincheira da luta, o que implica na imposição ao Estado de um projeto educacional politécnico, no espírito proposto por Marx. Acontece que essas exigências só adquirem sentido na medida em que abram caminho "para o florescimento de uma nova sociabilidade livre de toda forma de opressão e de exploração do homem pelo homem" (idem, p. 98). 
Em suma, qualquer proposta de educação, do ponto de vista da classe trabalhadora, não pode estar dissociada de um projeto estratégico de luta por uma transformação radical da sociedade, e, consequentemente, não deve estar desvinculada do embate político calcado nos interesses dos trabalhadores e de suas respectivas organizações. Do contrário, esse tipo de proposição leva água ao moinho dos que almejam separar as contendas em torno de reformas sociais das diligências com vistas à superação da ordem do capital.

Evidentemente, há suspeitas e objeções a esse olhar mediatizado à volta dessas questões que, em última análise, dizem respeito à formação humana, notadamente do trabalhador. Grosso modo, duas tendências se emblocam quando a discussão se encaminha por esse trilho. Há os que pensam que a educação abarca uma legalidade própria que, de modo algum, deve ser tomada como algo relativo. É quase como se esse campo da vida social pudesse tudo, inclusive oferecer uma formação integral, não ao indivíduo-trabalhador, simplesmente, mas ao trabalhador como classe. Na trincheira oposta, há os que, mediante a admissão dos limites peculiares da esfera educativa, costumam situá-la num plano de tal maneira secundário, que é quase como se pedissem desculpas de reivindicá-la ou a deixassem sempre como última opção, num plano mais do que acessório. Nesse caso, a educação aparece como um tigre de papel.

Faz tempo que o marxismo, de modo geral, trata essa questão com o mínimo de equilíbrio analítico, admitindo os limites da educação como complexo social, mas, ao mesmo tempo, reconhecendo a importância de torná-la acessível aos trabalhadores; não somente tornando-a formalmente franqueável aos que vivem da venda de sua força de trabalho, mas contribuindo, também, no plano do seu desenvolvimento humano. A esse respeito, Costa (2010, p. 177) assinala que:

\footnotetext{
A educação é o solo particular onde se articula o processo de humanização por parte do indivíduo, que se apropria de valores, habilidades, conhecimentos, costumes, formas de pensar e agir, entre outras objetivações produzidas pelo desenvolvimento histórico da humanidade.
}

A questão se coloca concretamente nos seguintes termos: as objetivações produzidas pelo desenvolvimento histórico da humanidade devem estar ao alcance da classe trabalhadora, que não pode receber unicamente o que deriva de um modelo de educação em que o princípio norteador é o próprio trabalho, não em sua perspectiva

\begin{tabular}{|l|l|l|l|l|}
\hline Qevista Dialectus & Ano 3 & n. 9 & Setembro - Dezembro 2016 & p. $100-112$ \\
\hline
\end{tabular}


emancipatória, mas, incomodamente, em sua versão estranhada, inerente ao domínio do capital.

Isso evoca, uma vez mais, os pressupostos que embasam o pensamento de Costa, para quem "O complexo da educação é muito mais do que um simples canal de continuidade histórica do ser social, ele é um mecanismo essencial para a entificação do homem historicamente determinado" (2010, p. 177). Para o autor citado, a sociedade burguesa enseja um sistema de educação formal que pode oferecer como possibilidade "a aquisição de objetivações genéricas necessárias". O problema é que esse sistema específico tem como horizonte histórico não a superação, mas a preservação da sociabilidade burguesa. Esse limite histórico é a linha demarcatória extrema do complexo da educação. Reivindicá-lo como direito público não é o mesmo que se deixar ofuscar pela direção que lhe é imposta pelos interesses sociais das classes dirigentes. Superar essa divisa da ordem social, que corresponde a esse período histórico, é condição necessária para que a humanidade, enfim, possa usufruir de uma educação definitivamente emancipadora.

Demonstrado este fato, resta ainda enfatizar como a luta de classes e o chamado "mundo do trabalho" devem ser perpassados pelo combate em torno de reivindicações que compreendam e abarquem temas e propostas que tomem a educação, não como simples reverberação da sociabilidade capitalista, mas como condição necessária para o desenvolvimento do ser social. Malgrado os limites desse processo, ele pode oferecer aos trabalhadores a possibilidade de um propício contato com as objetivações históricas produzidas, em escala densa, pela humanidade. Esse contato é necessário para que o trabalhador - ao longo de sua trajetória - possa ver além da sociedade de mercadorias. No quadro das limitações existentes, sem se deixar seduzir pela estratégia reformista, certamente, essa não é uma questão de todo desprezível.

\section{Considerações finais:}

Neste texto, buscamos trazer a lume as contradições do processo de formação humana no âmbito do capitalismo, mostrando como este concebe o trabalho unicamente como fator de valorização do capital - e como isso não exclui o elemento da violência contra o indivíduo humano e, finalmente, os modos de manifestação desses processos no complexo da educação.

Depreendemos do estudo que se finaliza que, embora a aspereza e a crueldade do capital cobrem seu preço no que diz respeito à formação dos indivíduos, redundando

\begin{tabular}{|l|l|l|l|l|}
\hline Qovista Qialectus & Ano 3 & n. 9 & Setembro - Dezembro 2016 & p. $100-112$ \\
\hline
\end{tabular}


em deformações nas atividades de instrução daqueles que vivem da venda de sua força de trabalho, é essencial e decisivo que os trabalhadores e as suas entidades representativas não se furtem a incluir na pauta reivindicatória a exigência de que o Estado ofereça ensino público, gratuito e de qualidade. Por dentro dessa luta, a demanda de uma crítica às formas institucionais conservadoras de instrução pública deve vir acompanhada da defesa de uma educação que aponte não para a preservação da ordem brutal existente, mas, antes de tudo, no sentido de investir com ímpeto para além de seus toscos limites, quando a educação, finalmente, deixará de ser vista como certo adestramento para o trabalho e passará a ser entendida como expressão mais candente da liberdade humana.

\section{Referências:}

ALBUQUERQUE, Sharly et Chan Nunes de; MENEZES, Ana Maria Dorta de. O trabalho como princípio educativo: elementos de um debate em aberto. In: MENEZES, Ana Maria Dorta de et al. (Orgs.) Trabalho, educação, Estado e a crítica marxista. Fortaleza: Edições UFC, 2009.

COSTA, Frederico Jorge Ferreira (org.). Marxismo, história e educação, in: Vozes da FACEDI - reflexões, experiências e perspectivas em educação, Fortaleza: EDUECE, 2010.

MARX, K. O capital, livro I, São Paulo: Boitempo, 2013.

ORTEGA, Jorge. Primeira chamada, in: Cult n. 218, novembro de 2016.

ZOLA, Émile. Germinal, São Paulo: Nova Cultural, 1996.

n. 9 